\title{
Comparative study between phenol red thread test and the Schirmer's test in the diagnosis of dry eyes syndrome
}

\author{
Estudo comparativo entre o teste fenol vermelho e o teste \\ de Schirmer no diagnóstico da síndrome do olho seco
}

Guilherme Mafra Ghislandi', Gina Carriero Lima²

\begin{abstract}
Objective: To investigate the correlation between phenol red test and Schirmer tear test on tear quantification together with a questionnaire to detect symptoms of dry eye. Methods: A total of 49 patients were enrolled at this study. Each participant had its eyes examined by the two tests. The dry eye symptoms were evaluated by a total of 5 questions. The data were collected and analysed by Kappa statistical method to check the concordance between the tests. Results: A sum of 65.3\% of the patients referred dry eye symptoms. When grouping them by age, $70.5 \%$ of the patients older than 60 years had symptoms, while in the group of 40-59 years, 59.3\% reported symptoms. Schimer tear test was positive for dry eye in $51 \%(25)$ of the patients, against $65.3 \%(32)$ in the phenol red test. Kappa value between the tests were 0.548, which indicates a moderate agreement of the them. Conclusion: The symptomatic questionnaire showed a higher frequency of dry eye in the elderly. Kappa value displayed an moderate agreement, which is relevant, specially because neither of the tests are the gold standard for the diagnosis of dry eye, and for the variability of results that testing can bring.
\end{abstract}

Keywords: Dry eye syndromes; Tears; Diagnostic techniques, ophthalmological; Cornea; Comparative study

\section{RESUMO}

Objetivo: Investigar a concordância entre o teste fenol vermelho e o teste de Schirmer para quantificação lacrimal junto a um questionário para detectar sintomas de olho seco. Métodos: No total, 49 pacientes participaram do estudo. Cada participante teve um olho examinado pelos dois testes. Os sintomas de olho seco foram avaliados através de 5 perguntas. Os dados foram coletados e depois analisados pelo método de estatísticas Kappa para avaliar a concordância entre os testes. Resultados: A sintomatologia foi positiva em 65,3\%(32) pacientes. Em grupos de idade, pacientes com 60 anos ou mais tiveram sintomatologia em 70,5\% das vezes, enquanto no grupo de 40-59 anos foram positivos 59,3\%. O teste de Schirmer foi positivo para olho seco em $51 \%(25)$ dos pacientes, enquanto o teste fenol vermelho foi positivo em $65,3 \%(32)$. O valor de Kappa entre os testes foi de 0.548 , demonstrando uma concordância moderada entre eles. Conclusão: A realização do questionário sintomático evidenciou uma maior sintomatologia de olho seco nos pacientes de maior idade. O valor de Kappa resultou em uma concordância moderada, considerada relevante, principalmente pelo fato de nenhum dos dois testes ser o padrão ouro para o diagnóstico de olho seco e pela variabilidade de resultados que os testes podem trazer.

Descritores: Síndromes do olho seco; Lágrimas; Técnicas de diagnóstico oftalmológico; Córnea; Estudo comparativo

\footnotetext{
${ }^{1}$ Scholar at the Medicine Course at Universidade do Sul de Santa Catarina, Tubarão, SC, Brasil.

${ }^{2}$ Universidade do Sul de Santa Catarina, Tubarão, SC, Brazil.

Institutions to which the study should be attributed: Universidade do Sul de Santa Catarina (UNISUL).

The authors declare no conflicts of interests.

Received for publication 10/05/2016 - Accepted for publication 08/10/2016.
} 


\section{INTRODUCTION}

$\mathbf{T}$ he dysfunction of the tear film, better known as dry eye syndrome or keratoconjunctivitis sicca, is a multifactorial disease of the tear and ocular surface. ${ }^{(1-3)}$ The tear film was detailed by Wolff( ${ }^{(4)}$ in 1946, as a structure of 7-10 $\mu$ thick whose main functions are: lubrication of the ocular surface, antibacterial activity, oxygenation, nutrition, and formation of a refractive optical surface. ${ }^{(5)}$

Dry eye can be the result of weaknesses in the preproduction of the tear film, in qualitative dysfunction of it, or due to problems in its secretion. It results, then, in a complex of several symptoms from discomfort, visual disturbances and tear film instability to potential damage of the ocular surface..$^{(1-3)}$

The prevalence of symptoms of dry eye increases with age and, several studies report it in $15 \%$ to $20 \%$ of the population, depending on the criteria used in each study to define the syndrome. ${ }^{(6,7)}$ It is difficult to estimate the exact prevalence of the disease, since the data are dependent on medical evaluations, being from experts in ophthalmology or not, and from data collected in questionnaires applied by the population in general, which comprises a measurement bias. Still, even the medical assessments have a predisposition to present different prevalences according to the test used for diagnosis. ${ }^{(8)}$

In addition to age, dry eye is more observed in black and Asian women. Among the risk factors, we can include the use of computers, contact lenses and certain drug classes; and the presence of comorbidities, such as rheumatoid arthritis, hyperlipidemia and degenerative arthritis. (9-11) $^{-1}$

The diagnosis of the syndrome is based on the patient's symptoms and medical history. The use of diagnostic tests that are currently available and external examinations are also indispensable in ophthalmic assessment in order to decide on the most appropriate treatment. ${ }^{(12)}$

Attempts to develop a simple test for measuring the functional production of tear, its secretion, residual volume and which do not bring harm to patient date back more than 100 years. Currently, Fluorophotometry, Schirmer's test and phenol red thread are all recognized as applicable methods for quantifying the tear. However, each of these techniques has biases that prevent the correct interpretation of their results. ${ }^{(13)}$ Therefore, there is no test or gold standard criterion for the diagnosis of dry eye.(2)

Among the quantitative diagnostic tests, the most used in practice is the Schirmer's test. Despite being simple and inexpensive, it is necessary to put paper strips into the eyes of the patient, which can bring discomfort. The problem, however, can be minimized through the use of local anesthetic. ${ }^{(14)}$ Among other disadvantages of the method are the long time (5 minutes), and the possible changes in the reliability of the test because the paper strip can absorb the tears unevenly or even be lost by evaporation. ${ }^{(1)}$

The phenol red thread introduced in 1982 was developed as an attempt to overcome the disadvantages of the Schirmer's test, as described in the previous section, including the high variability and low reproducibility for the detection of dry eyes. ${ }^{(15)}$ The test consists of a yellow cotton yarn impregnated with phenol red, which is sensitive to $\mathrm{pH}$ and, when wet by the tear that is slightly alkaline, changes its color from yellow to red. The length of the red color in millimeters is then measured. ${ }^{(13)}$

Although the two tests are similar in method, the potential benefits of the phenol red thread include the fact that there is little or no trouble with the feel of the yarn, which brings two benefits: there is no need for anesthetics, and there is less lacrimal reflex, increasing the reliability of tear test. In addition, the test time is only 20 seconds in each eye, which remains open and free to blink. ${ }^{(15,16)}$

Based on the foregoing, the phenol red thread has more theoretical advantages than the Schirmer's test. This study aimed to investigate the correlation between both tests in lacrimal quantification, along with a questionnaire for detecting dry eye symptoms, in order to establish whether, despite all methodological comforts of the phenol red thread, it also consists of the same diagnostic accuracy of the Schirmer's test.

\section{Methods}

A comparative study was carried out between the phenol red thread and the Schirmer's test during the months of February and August, 2015. The sample was composed of 49 patients seen in at Ambulatório de Especialidades Médicas da UNISUL (Universidade do Sul de Santa Catarina), in the Department of Ophthalmology located in the city of Tubarão, Santa Catarina, Brazil.

The study included all patients aged 40 years or older who were treated at Ambulatório de Especialidades Médicas da UNISUL in the period between February and August, 2015, who signed the Informed Consent. The study excluded those who wore contact lens, who underwent prior eye surgery or who mentioned any disease that could harm both the patient and the accuracy of the study, such as conjunctivitis.

First, the medical history of dry eye symptoms was assessed through six questions drawn up based on the literature ${ }^{(2,16)}$ : Do you feel your eyes dry? Do you feel sand in your eyes? Do you feel your eyes burning? Do your eyes get red? Can you notice secretions in your eyelashes? Have you ever woke up one day with your eyes glued? Patients who had at least one answer "sometimes" or "always" were considered with positive symptoms for dry eye. Then the standard clinical examination proceeded, including general physical examination and examination of the eye fundus.

After that, the Schimer's test and the phenol red thread were carried out by a trained ophthalmologist in all patients, regardless of whether they had positive symptoms of dry eye or not. One eye of each patient was randomly selected to be examined by the two tests. The order of performance of the tests was chosen at random, by flipping a coin. The second test was performed with a difference of at least 5 minutes after the first one to avoid that one test would interfere on the result of the other. The tests were applied in closed environment, with no wind.

\section{Schirmer's test}

Strips of the Schirmer's test were used according to the manufacturer's instructions. No local anesthetic was used. The Schirmer's test is made using a $35 \mathrm{~mm}$ long and $5 \mathrm{~mm}$ wide paper strip. One millimeter from the tip of the strip is folded and inserted 
into the lower fornix, and the patient is advised not to close the eyes and blink normally. The strip is removed 5 minutes afterwards, and the wet portion below the folded edge is measured immediately. The results were interpreted as follows: d"10 mm as positive for dry eye, and $>10 \mathrm{~mm}$ as normal tear production.

\section{Phenol Red Thread}

The test cords were plated in phenol red and sterilized in a plastic envelope. The folded portion was opened at an angle that made possible the easy placing on the lateral third of the lower eyelid. The cord was yellow (acid), but changed to a bright red color when got in contact with the tear. The patients were told to keep their eyes open in primary position of staring and blinking normally. No local anesthetic was used. After 20 seconds timed on a digital watch, the cord was removed and the wet portion (red) was measured from the tip, regardless of the fold. The results were interpreted as follows: d"10 $\mathrm{mm}$ as positive for dry eye, and $>10 \mathrm{~mm}$ as normal tear production.

After each test, the patient was questioned if there was discomfort during the tests, and the answer could be yes or no.

The data was stored in Microsoft Office Excel 2007, version 5.0, and processed and analysed using the progam SPSS (Statistical Package for the Social Sciences Inc, Chicago, United States) version 20.0. The method used was Kappa statistics to assess the correlation between the two tests (Kappa $=0$ means no concordance and Kappa $=1$ total concordance).

The present study followed all ethical precepts that are required, in accordance with resolution 466/2012, and is registered with approval under protocol number 39402314.3.0000.5369 of the Research Ethics Committee of UNISUL.

\section{RESULTS}

The sample comprised 49 patients who went to Ambulatório de Especialidades Médicas at UNISUL for ophthalmology care. The average age of the participants was 56 years, with standard deviation of \pm 11.5 years, ranging from 40 to 88 years.

Of the sample, $65.3 \%(32)$ of the patients reported symptoms of dry eye. Regarding the presence of symptoms and age, there was a higher prevalence of dry eye symptoms in older patients, because patients aged 60 years or more reported symptoms in $70.5 \%$ of the times, compared to $59.3 \%$ in the group from 40 to 59 years.

The Schirmer's test was positive for dry eye in 51\%(25) of the patients, and the phenol red thread in $65.3 \%(32)$. This data can be observed in table 1 . Regarding discomfort during the application of the tests, $14.3 \%$ (7) were uncomfortable during the phenol red thread, and $65.3 \%$ (32) considered the application of the Schirmer's test unpleasant.

Considering the correlation between the Schirmer's test and the phenol red thread, the Kappa coefficient was 0.548, demonstrating moderate concordance between the tests.

\section{Discussion}

Dry eye syndrome is a disorder of the tear film affecting millions of people worldwide. The symptoms affect people's quality of life, and are relatively common in the ophthalmic practice, especially in the elderly. ${ }^{(17)}$
Table 1

Positive results for the tests and symptoms

\begin{tabular}{lll}
\hline Test/Questionnaire & $\begin{array}{c}\text { Dry eye } \\
\text { n(\%) }\end{array}$ & $\begin{array}{c}\text { Normal } \\
\text { n (\%) }\end{array}$ \\
\hline Phenol Red Thread & $32(65.3)$ & $17(34.7)$ \\
Schirmer's test & $25(51)$ & $24(49)$ \\
Symptomatology & $32(65.3)$ & $17(34.7)$ \\
\hline
\end{tabular}

This study demonstrated a higher prevalence of symptoms in patients aged 60 years or more $(70.5 \%)$ compared to patients between 40 and 59 years (59.3\%). Reports suggest that elderly patients have intrinsic change of the ocular surface, which can justify the higher occurrence of symptoms in this population. (6) These data match the literature. An epidemiological study conducted in South Korea also showed the presence of dry eye symptoms being more prevalent in patients between 60 and 69 years. ${ }^{(18)}$

A study of Aditya Rege also found a significant increase in the prevalence of dry eye in elderly patients. As in people under 40 years dry eye prevailed in $6.06 \%$ of men and $10.09 \%$ of women, in those over 60 years the prevalence was $26.28 \%$ and $31.72 \%$, respectively. ${ }^{(19)}$ A study with elders in France detected positive symptomatology in $45.8 \%$ of people aged 80 years or more. ${ }^{(20)}$

As for the presence of symptoms of dry eye, comparatively, the various studies resulted in different prevalences. This can arise first due to the use of different questionnaires. In this study, patients who showed only one symptom were considered as positive symptomatology for dry eye, which may have been responsible for a significant increase in the prevalence. The differences between the results also occurred due the characteristics of the population of Ambulatório Médico de Especialidades at UNISUL. Patients are often referred to other specialities, which have a high prevalence of chronic diseases and make use of various medicines, which corroborates a lot to the increased prevalence of dry eye. ${ }^{(9-11)}$

Although the literature about dry eye tests is quite limited and has few articles published, especially regarding the phenol red thread, it is known that this test is less irritating and needs a much shorter time to be carried out compared to the Schirmer's test. ${ }^{(21)}$

In the present study, $51 \%$ of positivity were obtained for dry eye by the Schirmer's test, and $65.3 \%$ by the phenol red thread. These data are similar to those found by other authors in a comparative study between the tests, Santinder Vashit found a prevalence of dry eye syndrome in $64 \%$ of patients assessed by the Schirmer's test against $62 \%$ detected by the phenol red thread. ${ }^{(2)}$ In the study of TA Saleh, the detection rates were of $39.8 \%$ in the Schirmer's test and $31 \%$ in the phenol red thread. ${ }^{(16)}$

One of the advantages of the phenol red thread in relation to the Schirmer's test is the fact that its performance is more comfortable for the patient. ${ }^{(22)}$ In this study, the discomfort to perform the test was mentioned by $14.3 \%$ of patients compared to the phenol red thread, while $65.3 \%$ were annoyed by the application of the Schirmer's test. Data in the literature comparing the discomfort felt by patients for the accomplishment 
of the tests are scarce. This study found a high difference between the two tests, which reaffirms that the phenol red thread is much more comfortable for the patient.

The value of Kappa coefficient to assess the correlation between the Schirmer's test and the phenol red thread, according to the results of the present study, was 0.54 , demonstrating moderate concordance between the tests. These data are different from the comparative study conducted in India by Santinder Vashit, in which the Kappa value of 0.96 represented an excellent concordance between the tests ${ }^{(2)}$, and the study of TA Saleh, in which considerable concordance was established between the tests, with Kappa value of 0.3 . $^{(16)}$

Several studies have already reported the low correlation between the various tests to evaluate the lacrimal quantification. ${ }^{(23)}$ It can occur due to different mechanisms each study uses to differentiate a normal lacrimal quantity, and also dut to the differences between manufacturers of the tests and the intrinsic characteristics of the tests themselves.

Considering that the phenol red thread and the Schirmer's test may reflect various aspects of tear and produce different reflexes of tear production ${ }^{(24)}$, a moderate concordance between them can be considered relevant, mainly because none of the tests is the gold standard for the diagnosis of dry eye.

However, we can conclude that the ideal would be to perform both tests for the diagnosis of dry eye, as did Ivan de Monchy in his study, suggesting that the combination between the Schirmer's test the red phenol thread heavily improves the screening for patients with dry eye.(25)

It should be noted that this study has some limitations, as a relatively small sample number, requiring studies that address a larger population for a better correlation of data obtained between the tests. It is also noted that the tests, mainly the Schirmer's test, are subject to biases in the quantification of the tear, since the introduction in the eyes can cause tear reflex and overrate secretion, not matching the patient's amount of tear, besides being subject to change due to absorption of moisture from the environment.

There is also the need to emphasize the importance of conducting new researches with the phenol red thread the Schirmer's test and symptoms of dry eye, with the aim of complementing the scientific knowledge on the subject and standardize the diagnosis of dry eye syndrome.

\section{CONCLUSION}

The completion of the questionnaire showed a high presence of symptomatology for dry eye in patients, mainly in the elderly. It was observed that patients felt more discomfort with the Schirmer's test than with the phenol red thread.

The Kappa value between the two test resulted in a moderate concordance, considered relevant mainly because none of the two tests are the gold standard for the diagnosis of dry eye and the variability of results the tests can bring.

\section{ReFERENCES}

1. Abelson BM, Asbell P, Baudouin C, Beuerman WR, Bonini S, Bron A, et al. Dry Eye Workshop (DEWS) Committee. 2007 Report of the Dry Eye Workshop (DEWS). Ocul Surf. 2007;5(2):65-204.
2. Vashisht S, Singh S. Evaluation of Phenol Red Thread test versus Schirmer test in dry eyes: A comparative study. Int J Appl Basic Med Res. 2011;1(1):40-2.

3. Wei Y, Asbell PA. The core mechanism of dry eye disease is inflammation. Eye Contact Lens-Sci Clin Pract. 2014;40(5):248-56.

4. Floegel I, Horwart-Winter J, Muellner K, Haller-Schober EM. A conservative blepharoplasty may be a means of alleviating dry eye symptoms. Acta Ophthalmol Scand. 2003;81(3):230-2.

5. Lima G, Siqueira B, Cardoso H, Sant'Anna B, Osaki H. Avaliação do olho seco no pré e pós-operatório da blefaroplastia. Arq Bras Oftalmol. 2006;69(2):227-32.

6. Ottobelli L, Fogagnolo P, Guerini M, Rossetti L. Age-related changes of the ocular surface: a hospital setting-based retrospective study. J Ophthalmol. 2014;2014:532378.

7. Kastelan S, Tomic M, Salopek-Rabatic J, Novak B. Diagnostic procedures and management of dry eye. Biomed Res Int. 2013;2013:309723.

8. Bartlett JD, Keith MS, Sudharshan L, Snedecor SJ. Associations between signs and symptoms of dry eye disease: a systematic review. Clin Ophthalmol. 2015;9:1719-30.

9. Liu NN, Liu L, Li J, Sun YZ. Prevalence of and risk factors for dry eye symptom in mainland china: a systematic review and metaanalysis. J Ophthalmol. 2014;2014:748654.

10. Schaumberg DA, Sullivan DA, Buring JE, Dana MR. Prevalence of dry eye syndrome among US women. Am J Ophthalmol. 2003;136(2):318-26.

11. Kastelan S, Lukenda A, Salopek-Rabatic J, Pavan J, Gotovac M. Dry eye symptoma and signs in long-term contact lens wearers. Collegium Antropologicum. 2013;37(1):199-203.

12. Behrens J, Doyle J, Stern L. Dysfunctional tear syndrome: a Delphi approach to treatment recommendations. Cornea. 2006;25(8):900-7.

13. Senchyna M, Wax MB. Quantitative assessment of tear production: A review of methods and utility in dry eye drug discovery. Ocul Biol Dis Infor. 2008;1(1):1-6.

14. Hida RY, Dantas MC, Hida MM, Tsubota K. Estudo quantitativo da lágrima pelo teste de fenol vermelho na população brasileira. Arq Bras Oftalmol. 2005;68(4):433-7.

15. Moore JE, Graham JE, Goodall EA, Dartt DA, Leccisotti A, McGilligan VE et al. Concordance between common dry eye diagnostic tests. Br J Ophthalmol. 2009;93(1):66-72.

16. Saleh TA, McDermott B, Bates AK, Ewings P. Phenol red thread test vs Schirmer's test: a comparative study. Eye (Lond); 2006;20(1):913-5.

17. Bhatnagar KR, Pote S, Pujari S, Deka D. Validity of subjective assessment as screening tool for dry eye disease and its association with clinical tests. Int J Ophthalmol. 2015;8(1):174-81.

18. Um S-B, Kim NH, Lee HK, Song JS, Kim HC. Spatial epidemiology of dry eye disease: findings from South Korea. Int J Health Geogr. 2014;13:31.

19. Rege A, Kulkarni V, Puthran N, Khandgave T. A Clinical study of subtype-based prevalence of dry eye. J Clin Diag Res. 2013;7(10):2207-10.

20. Malet F, Le Goff M, Colin J, Schweitzer C, Delyfer MN, Korobelnik JF, et al. Dry eye disease in French elderly subjects: the Alienor Study. Acta Ophthalmol. 2014; 92(6):429-36.

21. Wee SW, Chun YS, Moon NJ, Kim JC. Clinical usefulness of the phenol red thread test as diagnostic tool in dry eye patient. J Korean Ophthalmol Soc. 2012;53(2):193-9.

22. Hamano H, Hori M, Mitsunaga S, Kojima S, Maeshima J. Tear test (preliminary report). J Jpn Contact Lens Soc. 1982;24:103-7.

23. Hua R, Yao K, Hu Y, Chen L. Discrepancy between subjectively reported symptoms and objectively measured clinical findings in dry eye: a population based analysis. BMJ Open. 2014;160(3):447-52. 
24. Tomlinson A, Blades KJ, Pearce EI. What does the phenol red thread test actually measure?. Optom Vis Sci. 2001;78(3):142-6.

25. Monchy I; Gendron G; Miceli C; Pogorzalek C; Mariette X; Labetoulle M. Combination of the Schirmer I and phenol red thread tests as a rescue strategy for diagnosis of ocular dryness associated with Sjögren's syndrome. Invest Ophthalmol Vis Sci. 2011 Jul 15;52(8):5167-73.

\section{Corresponding author:}

Guilherme Mafra Ghislandi

Rua Leoberto Leal, 96. Bairro Maluche. Brusque - SC. ZIP Code: 88354320

E-mail: guilhermeghislandi@me.com 